\title{
A Controvérsia Estados Unidos-Nicarágua e o Tema da Conduta das Partes
}

\author{
Vicente Marotta Rangel \\ Catedrático de Direito Internacional Público \\ Membro da "Corte Permanente de Arbitragem (Haia)" \\ Associado do "Institut de Droit International"
}

RESUMO: As sentenças proferidas em 1984 e 1986 pela Corte da Haia sobre a controvérsia entre Estados Unidos e Nicaragua contribuíram para o esclarecimento da questão da conduta dos Estados na ordern jurídica interestatal. Esse tema está vinculado ao da vontade dos Estados-partes e ao do estoppel. Ele já fora examinado em quatro controvérsias anteriores, dirimidas pela Corte internacional de Justiça: a) a do laudo arbitral do rei da Espanha; b) a do tempo de Préah Vihéar; c) a da Barcelona Traction; d) e, enfim, a da plataforma continental do Mar do Norte. Após examinar essas controvérsias e, mais particularmente, a existente entre Estados Unidos e Nicarágua, deduz o Autor duas conclusōes: a) a reafirmação da regra do efeito obrigatório dos atos de um Estado em relação aos direitos de outros Estados; b) a existência de prejuízo sofrido por um Estado em conseqüência da vontade de outro Estado, partes no mesmo litígio, como conditio sine qua do estoppel.

RESUMÉ: Les sentences rendues par la Cour de La Haye en 1984 et 1986 sur la controverse entre les Etats-Unis et le Nicaragua ont contribué à l'éclaircissement de la question du comportement des Etats dans l'ordre juridique international. Ce sujet est lie à celui de la volonté des Etats-parties et du stoppel. Il avait été déjà examiné dans quatre controverses soumises à la Cour internationale de Justice: a) celle de la sentence arbitrale du roi de l'Espagne; b) celle du temple de Préah Vihéar; c) celle de la Barcelona Traction; d) et enfin celle du plateau continental de la Mer du Nord. L'examen de ces affaires, en particulier celle concernant les relations entre le Nicaragua et les Etats-Unis, permet de dégager deux conclusions: a) la réitération de la règle de l'effet obligatoire des actes d'un Etat sur les droits d'autres Etats; b) l'existence d'un dommage subi par un Etat en conséquence de la volonté d'un autre Etat, les deux étant parties dans la même controverse, comme conditio sine qua de l'estoppel.

1) As recentes sentenças sobre a controvérsia entre a Nicarágua e os Estados Unidos da América se inscrevem entre as mais relevantes proferidas pela Corte Internacional da Justiça. A primeira delas, de 26 de novembro de 1984, relativas à competência do Tribunal e à admissibilidade do pedido da Nicará- 
gua $^{(1)}$, traz valiosa contribuição tanto sobre a temática do não comparecimento das partes e declarações de aceitação de jurisdição do tribunal como sobre a exegese dos artigos 36 e 53 dos Estatutos da Corte. Por seu turno, a segunda sentença, de 27 de junho de $1986^{(2)}$, além de aprofundar tópicos versados na decisão anterior, examina pontos essenciais adstritos ao mérito da controvérsia, a saber, os princípios básicos das relações internacionais e as relações entre fontes do direito internacional, sobretudo entre costumes e tratados internacionais. Mesmo rejeitadas frontalmente por uma das partes litigantes, ambas as sentenças constituem subsídios para a educação pública referente ao direito internacional da paz e da guerra na idade nuclear ${ }^{(3)}$.

Além dos tópicos acima referidos, outros há a considerar, como o das conseqüências jurídicas da conduta das partes. Embora esse tópico seja inquestionavelmente menor no contexto dos inseridos na medula da controvérsia ele oferece ensejo agora de reavaliação, sobretudo se cotejado com o que foi versado em controvérsias anteriores.

(1) Military and Paramilitary Activities in and against Nicaragua (Nicaragua v. United States of America), Jurisdiction and Admissibility, Judgement, I.C.J. Reports 1984, p. 392. Entre os comentários da sentença, vide BRIGGS, Herbert. W. "Nicaragua v. United States: Jurisdiction and Admissibility", American Journal of International Law, April 1985, vol. 79, pp. 373/378. Sobre a posição do governo dos Estados Unidos na controvérsia: FRANCK, Thomas M. "Icy Day at the ICJ", ibidem, pp. $379 / 384$ e D'AMATO, Anthony. "Modifying U.S. Acceptance of the Compulsory Jurisdiction of the World Court", ibidem, pp. 385/404. EISEMANN, Pierre Michel. “L'Arrêt de la C.I.J. du 26 Novembre 1984 (Compétence et Recevabilite) dans l'Affaire des Activités Militaires et Paramilitaires au Nicaragua et contre Celui-ci" Annuaire Français de Droit International, 1984, pp. 372/390; CANÇADO TRINDADE, Antonio Augusto. "Nicaragua versus Estados-Unidos (1984-1985)", Revista Brasileira de Estudos Políticos, julho 1986/janeiro 1987, pp. 139/170.

(2) "Military and Paramilitary Activities in and against Nicaragua (Nicaragua v. United States of America) Merits, Judgement, I.C.J. Reports 1986", p. 14. Entre os comentários da sentença, vide, inter alia os seguintes artigos ou comentários no American Journal of International Law, vol. 81, january 1987: HEIGHET Keigh, "Evidence, the Court, and the Nicaragua Case", pp. 1/56, BRIGGS, Herbert W. "The International Court of Justice Lives up to its Name", pp. 78/86; BOYLE, Francis A. "Determining U.S. Responsability for contra Operations under International Law", pp. 86/93; CHRISTENSON, Gordon A. "The World Court and the JUS COGENS", pp. 93/101; D'AMATO, Anthony. "Trashing Customary International Law", pp. 101/105; FALK, Richard. "The World Court's Achievement", pp. 106/112: FARER, Tom J. "Drawing the Right Line", pp. 112/116; FRANCK, Thomas M. "Some Observations on the ICJ'S Procedural and Substantive Innovations", pp. 116/121.

(3) FALK, op. cit., p. 108. 
2) O tema da conduta das partes não pode apartar-se da problemática da vontade dos Estados, vontade essa que relevância fundamental possui na ordem jurídica internacional, em particular no domínio da responsabilidade e da constituição das fontes do direito ds gentes. Explícita nos tratados ou implícita nos costumes internacionais, essa vontade persiste, embora mui diluida, no simples comportamento dos Estados, o qual não se reduz a atos isolados mas a uma série concordante dos mesmos a despeito de serem eventualmente informes, imprecisos, espaçados. O tema em questão constitui preliminar do princípio pelo qual cada parte está comprometida por sua conduta anterior. Malgrado a diversidade de termos com que esse princípio possa ser designado ("estoppel", preclusão, aquiescência, "forclusion"), tem ele sempre, no dizer do juiz J.R. Alfaro, a mesma substância: é inadmissível contradição entre pretensões ou alegações formuladas por um Estado e a sua prévia conduta em relação com as mesmas: allegans contraria non audiendus est. "Its purpose is always the same: a State must not be permitted to benefit by its own inconsistency to the prejudice of another State (nemo potest mutare consilium suum in alterius injuriam). A fortiori, the State must not be allowed to benefit by its inconsistency when it is through its own wrong or illegal act that the other party has been deprived of its right or prevented from exercising it (Nullus commodum capere de sua injuria propria). Finally, the legal effect of the principle is always the same: the party which by its recognition, its representation, its declaration, its conduct or its silence has maintained an attitude manifestly contrary to the right it is claiming before an international tribunal is precluded from claiming that right (venire contra factum proprium non valet) ${ }^{(4)}$.

3) São bastante numerosos os casos de arbitragem e de solução judiciária em que o princípio do efeito obrigatório dos atos próprios de um Estado em relação a direitos em litígio com outro Estado esteve posto em causa ${ }^{(5)}$. Entre es-

(4) "Separate Opinion of Vice-President Alfaro" I.C.J. Reports 1962, p. 40.

(5) Vide relação das controvérsias, verbi gratia, no voto individual do juiz ALFARO (ibidem). Entre os laudos arbitrais, em que o princípio do efeito obrigatório dos atos próprios se aplica, posteriores a esse voto, está a sentença de 22 de setembro de 1963 relativa ao acordo de trânsito aéreo entre os Estados Unidos e a França (Revue Générale de Droit International Public, Paris, Pedone, 1979). 
ses casos ou paralelamente com eles estão as controvérsias em que foi debatido o estoppel ${ }^{(6)}$ cujas origens se identificam com aquele princípio. Com base nas sentenças judiciais ou arbitrais referentes a essas controvérsias muito haveria para dizer. A nossa intenção se restringe a tecer breves considerações sobre a recente controvérsia entre Nicarágua e Estados Unidos à luz de alguns litígios dirimidos pela Corte Internacional de Justiça.

A doutrina se interessou sobremaneira por questōes atinentes à conduta das partes ${ }^{(7)}$, entendendo divisar em várias das decisōes arbitrais ou judiciais o reconhecimento de efeitos jurídicos de uma série de atos que os Estados praticavam sem terem consciência de alcançar a criação de novas relaçōes de direito. "Contrariamente ao que se passa no caso dos atos jurídicos internacionais, os Estados, ao realizarem tais atos, não tinham a intenção de produzir os efeitos de direitos que os juízes lhes atribuiram"(8).

4) Assinale-se a existência de liame significativo entre a recente controvérsia Nicarágua-Estados Unidos e a controvérsia sobre o laudo arbitral do rei da Espanha ${ }^{(9)}$. É que na controvérsia com os Estados Unidos, a Nicarágua invocou a sua própria conduta com referência à declaração que fizera a 24 de setembro de 1929, de reconhecimento da competência da Corte Internacional de Justiça em consonância com as disposições dos $\$ \S 2^{\circ}$ e $5^{\circ}$ do artigo 36 do Es-

(6) Vide rol das controvérsias verbi gratia in PECOURT GARCIA, Enrique, "El princípio del Estoppel en Derecho Internacional", Revista Española de Derecho Internacional, 1962, pp. 98-139 e MARTIN, Antoine. L'Estoppel en Droit International Public, Paris, Pedone, 1979.

(7) Cf. SPERDUTI, "Prescrizione, consuetudine e acquiescenza in diritto internazionale". Rivista di Diritto Internazionale, 1961, pp. 3-15. BARALE, "L'acquiescement dans la jurisprudence internationale". AFDI, 1965, pp. 389-427. J.P. COT, "La conduite subsequente des Parties à um Traite". RGDIP, 1966, pp. 632-666. VENTURINI, "La portée et les effets juridiques des attitudes et des actes unilatéraux des Etats". RCADI, t. 112, 1964, pp. 367-461. CAHIER, Philippe, "Le comportement des Etats comme source de droits et d'obligations". Recueil d'Etudes de droit International en Hommage à Paul Guggenheim. Faculté de Droit de L'Université de Généve Institut universitaire de Hautes Etudes Internationales, Génève, 1968, pp. 237-265. JACQUE, Jean-Paul, Eléments pour une théorie de l'acte juridique en droit international public, Paris, JGDI, 1972, pp. 210 e segs. MIAJA de la MUELA, Adolfo. Introducción al Derecho Internacional Publico, Madrid, 1974, pp. 165-191. DIEZ de VELASCO, Instituciones de Derecho Internacional Publico, tomo I, 4⿳亠丷厂 ed., pp. 146-149. Vide também nota 18a, infra.

(8) CAHIER, Philippe, op. cit., pp. 239/240.

(9) "Case concerning the Arbitral Award made by the King of Spain on 23 December 1906, Judgement of 18 November 1960. I.C.J. Reports 1960, p. 192" 
tatuto desse Tribunal. Assim, a jurisdição da Corte, segundo a Nicarágua, era obrigatória para ambos os países, em virtude não apenas do artigo XXIV, parágrafo 2, do tratado de amizade, comércio e navegação, por ambos assinado a 24 de maio de 1958, senão também em consonância com aquela declaração da Nicarágua, a qual seria concordante, de resto, com a declaração dos Estados Unidos de 14 de agosto de 1946, formulada com base no artigo 36, parágrafo 20, do Estatuto. Segundo esta última disposição, os membros da Sociedade das Nações e os Estados mencionados no Anexo do Pacto da mesma Sociedade poderiam, por ocasião da assinatura ou da ratificação do Protocolo do Estatuto da Corte Internacional de Justiça, ou ulteriormente, declarar reconhecer "como obrigatória, de pleno direito e sem convenção especial", a jurisdição da Corte, em face de outro Estado que também reconhecesse. Assim o fizera a Nicarágua. Não bastava, porém, assinar o Protocolo: era necessário ratificá-lo, o que de fato sucedeu com a publicação, após a observância dos trâmites constitucionais, do ato formal conclusivo no órgão oficial (La Gazeta), a 18 de setembro de 1935. Alguns anos mais tarde, a 29 de dezembro de 1939, o Ministério das Relações Exteriores da Nicarágua enviou o telegrama seguinte à Sociedade das Naçōes: "Estatuto e Protocolo da Corte Permanente de Justiça Internacional da Haia já ratificados. Instrumento de ratificação será enviado oportunamente".

Em defesa da tese da competência da Corte Internacional de Justiça em relação à sua controvérsia com os Estados Unidos, a Nicarágua invocou também o artigo $36, \S 5$, do Estatuto dessa mesma Corte, o qual dispõe que nas relações entre as partes dele contratantes, "as declaraçōes feitas de acordo com o artigo 36 do Estatuto da Corte Permanente de Justiça Internacional e que ainda estejam em vigor serão consideradas como importando na aceitação da jurisdição obrigatória da Corte Internacional de Justiça, pelo período em que ainda devem vigorar e de conformidade com os seus termos".

Conquanto nenhuma prova existisse de que o instrumento de ratificação do Protocolo haja sido depositado, alegou a Nicarágua ter, ao ratificar o Estatuto da Corte Internacional de Justiça (que entrou em vigor a 24 de outubro de 1945), tornado perfeita a sua declaração de 1929; e que a procedência de sua tese se assentava, ademais, tanto na opinião dos publicistas e na prática dos Estados Unidos, como no comportamento das Partes e do governo de Honduras no decorrer da controvérsia entre este país e a Nicarágua (1957-1960) a propósito da sentença arbitral do rei da Espanha, de $1906^{(10)}$.

5) Nāo se desconhece a relevância alcançada pelo tema de conduta das Partes nesta última controvérsia. Contrariamente à alegação da Nicarágua, de que a decisão do rei Afonso XIII era desprovida de força obrigatória, entendeu a Corte que pelo fato deste país "ter livremente aceitado a designação do rei da Espanha como árbitro" e "ter participado plenamente do processo arbitral", 
nāo poderia ele posteriormente invocar as razões, que apontara, de nulidade da sentença ${ }^{(11)}$. A Nicarágua, "por suas declaraçōes expressas e por sua conduta" - aduziu a Corte - "tinha reconhecido a caráter válido da sentença e não estava mais no direito de dissentir desse reconhecimento", manifestado durante vários anos, "para contestar a validade da sentença"(12). Discreparam a respeito os juízes Moreno Quintana e Sir Percy Spender, embora ambos subscrevessem a sentença do Tribunal. Enquanto para o primeiro, a alegação da aquiescência da Parte tinha "um valor subsidiário" e fornecia "um argumento processual" sem constituir "uma razão jurídica suficiente para dar fundamento à sentença"(13), para o segundo juiz, ao contrário, a conduta da Nicarágua, "antes e durante a arbitragem", a proibia de invocar "qualquer irregularidade" com referência a essa designação"(14).

6) Igualmente, em sua sentença de 15 de junho de 1962 (fundo) sobre o templo de Préah Vihéar, a Corte necessitou de decidir sobre os efeitos jurídicos da conducta de uma das partes. Na controvérsia sobre esse templo e suas cercanias, o Camboja alegava a violação de seus direitos soberanos em relação à area litigiosa enquanto a Tailândia sustentava que o território em disputa estava situado dentro de suas fronteiras e sujeito a sua soberania. O litígio tinha suas origens nas negociaçōes ocorridas de 1904 a 1908 entre, de um lado, a França (então Potência protetora da Indochina francesa, da qual o Camboja era parte) e, de outro lado, o Sião (como outrora se chamava a Tailândia). A Corte asseverou não poder a Tailândia negar, em razão de comportamento anterior, ter aceitado carta topográfica (anexo I do Memorial do Camboja) que, obra de oficiais franceses, entendia fixar a fronteira entre o Siāo e o Camboja. Ressalta da missiva endereçada, a 20 de agosto de 1908, pelo ministro do Sião em Paris ao ministro das Relações Exteriores em Bangkok, que a carta do anexo I fora transmitida como pretendendo representar o resultado dos trabalhos de delimitação. Não reagiram as autoridades siamesas nem na época nem posteriormente, o que levaria a supor que concordaram com essa delimitação. A Corte entendeu, em conseqüência, que a aceitação pelas Partes dessa carta importava na incorporação da mesma às cláusulas convencionadas pelos litigantes no começo do século ${ }^{(15)}$.

(11) I.C.J. Reports 1960, p. 209.

(12) Ibidem, p. 213.

(13) Ibidem, p. 218. O voto individual de MORENO QUINTANA se revela coerente, de certo modo, com o voto vencido que a seguir proferiria na questāo do Templo Préah-Vihéar. Cf. I.C.J. Report 1962, pp. $67 / 74$.

(14) Ibidem, p. 219.

(15) I.C.J. Reports 1962, p. 23, 32 et 33. 
Deu a Corte, assim, aplicação ao princípio do comprometimento da parte por sua conduta anterior, embora se pudesse dizer que ele necessitaria de aprofundamento $^{(16)}$ e de respaldo maior nas provas então produzidas ${ }^{(17)}$

7) A controvérsia sobre a Barcelona Traction suscitou, quanto às duas primeiras exceções arguidas pelo Estado demandado, ensejo de examinar a atitude das partes (tanto do governo belga de início, como em seguida do governo espanhol) no tocante ao alcance da desistência da Bélgica na demanda anterior e à competência da Corte para conhecer do litígio. Um aspecto particular desse exame ${ }^{(18)}$ disse respeito ao argumento do estoppel invocado pelo Estado demandado, tendo a Corte perfilhado um conceito restrito dessa doutrina, pelo qual esta pressuporia uma reunião de diversos elementos de técnica jurídica correspondentes $^{(19)}$ ao mesmo conceito no direito anglo-americano. Entendeu a Corte assistir razão nesse ponto ao Estado demandante, uma vez que esses elementos não existiam ou não foram provados: um certo comportamento enganador imputável a esse Estado do qụal resultassem prejuízos ao Estado demandado $^{(20)}$.

8) Tal entendimento ficou reforçada quer pela alegação da Dinamarca e da Holanda, quer sobretudo pela sentença da Corte, de 20 de fevereiro de 1969, em relação à controvérsia sobre a Plataforma Continental do Mar do Norte. Embora aqueles países tivessem assinado e ratificado a Convenção de 1958 sobre a plataforma continental, a República Federal da Alemanha a havia somente assinado. Sem embargo, entendiam eles que a Convenção era obrigatória para este país em razão da subscrição do compromisso de obedecer ao tratado. Alegaram ter o mesmo Estado se apresentado "como aceitando o regime convencional e como reconhecendo a aplicação desse regime, de uma forma que teria levado outros Estados, em particular a Dinamarca e a Holanda, a moldar as suas atitudes',(21). Mas a corte rejeitou o argumento de estoppel tanto por ca-

(16) "Separate Opinion of Sir Gerald FITZMAURICE, Ibidem, p. 62.

(17) “Dissenting opinion of Sir Percy SPENDER, Ibidem, p. 131.

(18) C.I.J. Report 1964, pp. 22/25.

(19) Sobre o estoppel no direito internacional, cf. extensa bibliografia citada por VALLÉE, Charles. "Quelques Observations sur l'Estoppel en Droit des Gens" RGDIP, 1973, pp. 950/951 e por MARTIN, Antoine, op. cit., pp. 65 e segs.

(20) LOUIS, Jean-Victor, “L'Estoppel devant la Cour internationale de Justice", Revue de droit international et de Droit Comparé, 1965, p. 219.

(21) C.I.J. Recueil 1969, p. 25, par. 27. 
rência de provas das alegações da Dinamarca e da Holanda como em razão do próprio conceito deste instituto. Para que o estoppel existisse - disse o tribunal - era necessário que aquele país não pudesse contestar a existência convencional em razão de uma conduta, declaraçōes, etc., que não teriam apenas mostrado de modo claro e constante a sua aceitaçāo desse regime mas teriam igualmente conduzido a Dinamarca e a Holanda, fundando-se nessa atitude, a modificarem de posição em seu próprio detrimento ou a sofrerem um prejuizo qualquer", o que na espécie não fora comprovado ${ }^{(22)}$.

9) A recente controvérsia deu ensejo à Corte Internacional de Justiça de reafirmar as duas diretrizes no tocante à questão mais geral da conduta das partes assim como ao tópico mais particular do estoppel. Teria de fato a Nicaragua reconhecido sempre, desde a sua declaração de 1929 , a jurisdição obrigatória da Corte Internacional de Justiça? A resposta a essa pergunta levou o Tribunal a evocar a conducta da Nicarágua em sua controvérsia com Honduras. Feito o retrospecto, entendeu a Corte que mesmo se essa conduta "não fora isenta de ambiguidade", a Nicarágua jamais declarou não estar vinculada por sua declaração de 1929. Ora, esse silêncio, segundo o Tribunal, "tendo em conta a natureza pública e constante das afirmações oficiais referentes ao compromisso na Nicaragua segundo o sistema da cláusula facultativa", não poderia ser interpretado senão como uma aceitação da jurisdição obrigatória. Assim o entendeu a Corte, a qual concluiu, diz a sentença de 1984, ter ficado a sua competência "identicamente estabelecida" no caso de ser a Nicarágua o demandante" $"(23)$.

10) Tal conclusão foi, ademais, robustecida pelas publicações da Corte e do Secretariado da ONU, nas quais a Nicarágua figura entre os Estados vinculados à competência obrigatória ${ }^{(24)}$. Afirmou-se ter esse país cumprido as formalidades necessárias à sua vinculação a jurisdição obrigatória da Corte ${ }^{(25)}$

(22) Ibidem, p. 26, par. 29.

(23) I.C.J. Report 1984, par. 39 Vide, porém, dúvidas ou objeções suscitadas sobre a conduta da Nicaragua de reconhecimento de sua vinculação à Corte com base no $\S 2$ do art. 36 do Estatuto: "Separate Opinion of Judge Ago", Ibidem, pp. 36/40.

(24) Ibidem, par. 42. Em oposição à interpretação da Corte sobre alcance dos Anuarios da Corte, vide "Separate Opinion of Judge Sir Robert Jennings" I.C.J. Report 1984, pp. 540/545; "Separate Opinion of Judge Oda". I.C.J. Report 1984, pp. 485/488; "Dissenting Opinion of Judge Schwebel" I.C.J. Report 1984, par. $41 / 47$.

(25) Ibidem, par. 46. 
Ficou a Nicaragua, assim, em uma situaçāo excepcional. Tendo em conta a origem e a generalidade dessas afirmações, a constante aquiescência desse Estado às mesmas constitui - no dizer da Corte - um modo válido de manifestação da Nicaragua em reconhecer a competência obrigatória do Tribunal. A Nicaragua é, pois, em relação aos Estados Unidos, um Estado aceitando "a mesma obrigação", em conformidade com o artigo 36, parágrafo 2, do Estatuto ${ }^{(26)}$

Ao analisar a conduta dos Estados Unidos, a Corte entendeu que dela não emergia oposição à pretensão da Nicaragua de reconhecimento da jurisdição da Corte, pois a missiva daquele país, de 6 de abril de 1984 (pela qual se modificaram os termos da declaração de 14 de agosto de 1946), "parece denotar que os Estados Unidos, bem como os demais Estados, consideravam nessa data que a Nicaragua estava ligada pela competência da Corte segundo os termos de sua declaração de 1929 '"(27)

12) Objetou, porém, aquele país que, mesmo se a Nicaragua tivesse base para invocar a jurisdição da Corte nos termos do artigo 36, parágrafos 2 e 5 , do Estatuto, a conduta do país centro-americano constituiria impedimento para invocá-la. Desde 1943, alegam os Estados Unidos, a Nicaragua os induziu constantemente a pensar que ela não estava ligada à cláusula facultativa e, portanto, ela se encontraria impedida pelo estoppel de ser beneficiada com o reconhecimento de jurisdição obrigatória contra os Estados Unidos ${ }^{(28)}$. Teria procedência a alegação do estoppel? Entendeu a Corte que não. A conduta da Nicaragua no dizer da sentença foi "sem equívoco" no sentido de consentir estar vinculada pela cláusula facultativa. Os dois casos citados em sentido contrário pelos Estados Unidos não seriam suficientes para comprometer a tese da Nicaragua. Por outro lado, fazia-se necessário que a conduta de um Estado induzisse outro Estado a modificar a sua posição e que este sofresse detrimento ou prejuízo. "A Corte não pode considerar - disse a sentença - que a invocação pela Nicaragua da cláusula facultativa seja de algum modo contrária à boa fé ou à equidade; também não se pode dizer que o critério adotado nas controvérsias da Plataforma continental do mar do Norte valha para a Nicaragua; e portanto o estoppel invocado pelos Estados Unidos à Nicaragua não é aplicável'(29).

(26) Ibidem, par. 47.

(27) Ibidem, par. 41.

(28) Ibidem, par. 49 e 50.

(29) Ibidem, par. 50. Como posição crítica à conclusão da sentença em relação a esse parágrafo, vide "Separate Opinion of Judge Oda" ICJ Reports 1984, pp. 488 e 489; "Separate Opinion of Judge Ago", Ibidem, par. 36 a 39; "Dissenting Opinion of Judge Schwebel". I.C.J. Reports 1984, par. 53-62. 
A questão da conduta foi retomada em votos individuais ou dissidentes. Embora o juiz Ruda considerasse estar a Nicaragua vinculada à jurisdição compulsória da Corte, a razão dessa vinculação estaria não tanto na conduta das partes, e em particular desse Estado, mas no fato de ter a Nicaragua preenchido "a única condição necessária", segundo o mesmo juiz, "para tornar aplicável uma declaração feita nos termos do artigo 36 , parágrafo 2 e em conformidade com o parágrafo 4 do mesmo artigo", ou seja, "o depósito da declaração com o Secretario Geral das Nações Unidas" Conquanto a conduta dos Estados seja "um elemento importante na interpretação das convenções", não é certo, porém, no dizer de Ruda, que essa conduta pudesse "acarretar a aceitação das obrigaçōes internacionais enunciadas num tratado sem que seja respeitado o processo previsto para a entrada em vigor dessas obrigações",(30).

Objeta, por sua vez, o juiz Ago à conclusão a que a Corte chegou no tocante ao tema da conduta das partes. Contesta ele possa "a inquestionável exigência de um ato formal de aceitação ser substituída - sobretudo em um domínio tão especial e delicado como o da aceitação da obrigação de submeter as suas controvérsias internacionais à jurisdição da Corte - por uma simples conduta de fato, mesmo se a intenção revelada por essa conduta fosse inquestionável'(31)

13) Da análise da temática de conduta das partes no contexto da controvérsia entre Nicaragua e Estados Unidos, se infere, pois, a importância que essa conduta possui na interpretação das fontes de direito. Tal inferência constitui uma reafirmação das conclusões a que o exame de controvérsias anteriores conduz.

O cotejo dessas controvérsias ressalta possuir essa temática, no litígio em exame, um alcance proporcionalmente menor do alcançado em outros litígios, tendo em conta o maior número e a maior variedade de questões complexas versadas na recente controvérsia.

Nesta se afirma, claramente, como o fizeram as sentenças acima referidas, o princípio do efeito obrigatório dos atos próprios de um Estado em relação a direitos em litígios com outros Estados. Sem embargo do reconhecimento desse princípio no caso vertente, nele não se deu acolhimento à alegação do estoppel. Ambos se relacionam mas se distinguem. Reiterou a Corte que o estoppel pressupõe a existência de prejuizo sofrido por um Estado em razão de induzimento feito por outro Estado, ambos partes no mesmo litígio.

(30) Separate Opinion of Judge Ruda. I.C.J. Reports 1984, par. 29.

(31) "Separate Opinion of Judge Oda" I.C.J. Reports 1984, par. 31. 
Da recente controvérsia, dirimida pela Corte em duas etapas (1984 e 1986), se deduz também maior responsabilidade do Estado no referente ao acompanhamento da conduta de outros Estados. Nessa controvérsia as vinculações entre as partes eram bilaterais mas não de forma estrita. Tinham elas como base de referência documentos plurilaterais, de vocação universal, os Estatutos quer da Corte Permanente de Justiça Internacional, quer da Corte atual. Das sentenças proferidas a respeito se infere que os Estados necessitam de acompanhar a conduta não apenas de um determinado Estado mas de todos os demais, em uma perspectiva de alcance tanto bilateral quanto multilateral. 